Jpn. J. Ornithol. 48: 127-133, 1999

抱卵コストはオオセグロカモメのクラッチサイズを制約するか？

\author{
高橋康郎*・新妻靖章・帖地美千代・石川宏治・綿貫 豊
}

北海道大学農学部応用動物学教室 $\mathbf{T} 060-8589$ 札幌市北区北 9 条西 9 丁目

\title{
Is Clutch Size of Slaty-backed Gulls Determined by Incubation Cost?
}

\section{Yasuro TAKAHASHI*, Yasuaki NizUma, Michiyo CHOCHI, Koji IsHIKAWA and Yutaka WATANUKI}

Laboratory of Applied Zoology, Faculty of Agriculture, Hokkaido University, Kita-9, Nishi-9, Kita-ku, Sapporo, 060-8589, Japan

Gull (Laridae) species usually lay two or three eggs. We tested the hypothesis that clutch size is determined by incubation ability of parents in Slaty-backed Gulls (Larus schistisagus) whose normal clutch size is three on Teuri Island. Their clutch sizes were manipulated to be two-egg clutches where one egg was removed, three-egg clutches with no manipulation (control) and four-egg clutches where one egg was added. Hatching success and hatchling masses were not different between experimental and control groups. The mean incubation period of the four-egg clutches $(29.2$ \pm 1.9 days) was one day longer than that of the two-egg clutches (28.1 \pm 1.4 days $)$ and control ( $28.2 \pm 1.6$ days $)$. The mean egg temperature of four-egg clutches $\left(33.0 \pm 2.8{ }^{\circ} \mathrm{C}\right)$ was lower than that of two-egg clutches $\left(36.2 \pm 1.8{ }^{\circ} \mathrm{C}\right)$ and control $\left(35.9 \pm 1.8{ }^{\circ} \mathrm{C}\right)$. These results suggest that the parents can not incubate experimental enlarged clutches effectively but this does not affect offspring production.

Key Words: Clutch size, Incubation cost, Larus schistisagus, Slaty-backed Gull

鳥類のクラッチサイズ（一腹卵数）は，ある繁殖期に親が充分に給餌できる雛の最大数 に一致すると考えられている (Lack 1947). カモメ属の一腹卵数は $2 \sim 3$ 卵であり， 4 卵 以上産卵する個体はほとんど見られず（Conover 1984，Reid 1987a），3 卵が上限である. しかしながら, 雛数の操作実験によると, カモメ属の親鳥は 3 卵よりも多くの雊を巣立たせ られることが示されている (Harris \& Plumb 1965, Haymes \& Morris 1977, Winkler 1985). さらに, 親の生存率を測定し, 生涯の繁殖成功度を考慮に入れても，3卵がクラッ チサイズの上限となる明確な証拠は得られていない（Reid 1987b).

これまでの研究では, 産卵や抱卵のコストが考慮されていないために, クラッチサイズと

* 現所属 : ₹211-0053 川崎市中原区上小田中 1 -13-55

Present address: 1-13-55 Kamiodanaka, Nakahara-ku, Kawasaki 211-0053, Japan 
巣立ち可能な最大雛数に不一致が生じている可能性がある (Monaghan \& Nager 1997). 最近行われた研究において，1 卵目を除去することによって延べ 4 卵を産卵させられた 3 卵 を抱卵するニシセグロカモメ（Larus fuscus）の親鳥は, 自身のボディー・コンディション を低下させ，対照区より少ない雊しか巣立たせることができなかった（Monaghan et al. 1998)，この場合，4卵目を産卵するコストが，クラッチサイズの上限を決定していると考 えられる.

クラッチサイズの上限は，抱卵のエネルギーコストによって決定されている可能性あある. 抱卵に費やすエネルギーは抱卵数とともに増加するので, 通常より多くの卵を抱卵すると親 鳥のエネルギー消費量が増加することがホシムクドリ（Sturnus vulgaris），アオガラ (Parus caeruleus), マダラヒタキ (Ficedula hypoleuca) で確認されている（Biebach 1981, Haftorn \&. Reinertsen 1985, Moreno \& Carlson 1989). より多くの卵を抱卵す るために増加したエネルギー要求量に親鳥がうまく対応できず, 抱卵を効果的に行えなかっ たり，たとえ抱卵の効率が落ちなくてあ，育雊期やその後の親鳥の質に影響を与えるような 場合, 抱卵のエネルギーコストが，クラッチサイズの上限を決定していることになる．また， クラッチサイズの上限は, 親鳥の抱卵に関する形態的制約によっても決まるだろう. 大型力 モメ属の抱卵斑は腹部に 1 つと胸部に 2 つの計 3 つであるため, 4 卵を効率よく温められな いのかむ知れない (Pierotti \& Bellrose 1986).

本研究では, 効率的に抱卵できる卵の最大数が, オオセグロカモメ (Larus schistisagus) のクラッチサイズの上限を決定しているのかどうかを, 抱卵数を実験的に操作し, その孵化 率, 抱卵日数, 餒化雊体重, 卵温度及び抱卵している親鳥の体温を測ることによって評価 した.

\section{方法}

\section{1) 調查地と材料}

本研究は, 1998年に北海道苫前郡羽幌町天売島（北緯44度25分, 東経144度19分）で行 なった，島の周囲は $11.5 \mathrm{~km}$, 島の長径に沿い北西側は $50 \sim 100 \mathrm{~m}$ の切り立った崖になってお り, その崖の下部から上部にかけて, オオセグロカモメが集団繁殖する. その繁殖地内に調 查区を設置した。観察, 操作実験, 卵温と体温の測定を実施する上で, 環境庁と文化庁か ら許可を受けた.

\section{2 ) 抱卵数操作実験}

2 日に 1 回調查区を見回り, 初卵産卵が確認された巣に杭でマークした。それらの巣の すべての卵の産卵日を記録した，産卵日は，5月 1 日を 1 日目として計算した，産卵を確 認したときに，マジックペンで各々の卵に識別のため印をつけ，卵の短径と長径をノギスを

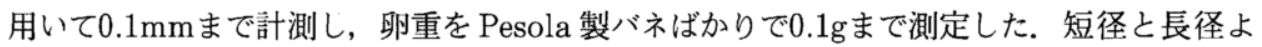
り次式を用いて卵体積を求めた。

卵体積 $(\mathrm{ml})=(\text { 短径 }(\mathrm{cm}))^{2} \times$ 長径 $(\mathrm{cm}) \times 0.476$ (Harris 1964).

実験には，5月 9 23日の間に初卵を産卵したペアのうち，3 卵を産卵したペアのみを 用いた。最終卵のc卵（産卵順に，a卵，b卵，c卵之呼ぶ）を産卵した 2 日後に，実験巣の 
産卵終了日と同日に産卵を終了した他の巣に卵を 1 個移動することによって，2 卵区（24 巣) と 4 卵区 (24巣) を作った. 移動する卵は，3卵の中から，無作為に選んだ。また， 3 卵を産卵した他の30巣には，何む手を加えずに対照区とした．これらの 3 つの実験区 （2 卵区，4 卵区，対照区）は，産卵を終了した巣をランダムに振り分けて作った，同日に 産卵を終了した巣がない場合には，3 卵区とした，実験区間で親の質が異なることがない ことを確かめるため, 操作する前の産卵日, 卵重と卵体積について一元配置の分散分析を 行い, Scheffeの方法で各抱卵数の間を多重比較した.

抱卵期は 1 日に 1 回すべての巣を見回り卵数を確認した。産卵されてから餒化するまで の期間（この期間を抱卵日数と呼ぶ）と親鳥の抱卵コストを評価することが目的であった ため, 卵が消失していたときは（3 卵区において 2 巣，4 卵区において 1 巣，すべて 1 卵 ずつ消失), 他の巣から産卵日の近い卵を加えて実験条件のクラッチサイズに戻した。餒化 率の分析では，消失した卵は餒化しない卵として扱った。

睬化の確認は, 1 日に 1 回すべての巣を見回り, 孵化日を記録し, 稃化直後の㮲の体重 をPesola 製バネばかりで0.1gまで計測した，産卵日と餒化日から，粰化したすべての卵の 抱卵日数を求めた. また, 卯孚化率を各操作実験区毎に求めた.

\section{3) 卵温度}

卵温の測定と記録には，温度測定用自動記録計（タバイエスペック社, RT-10）を用い た. 校正は水銀計を用いて $5.0^{\circ} \mathrm{C} ら ~ 42.0^{\circ} \mathrm{C}$ の間で $\pm 0.1^{\circ} \mathrm{C}$ 精度で行なった. 抱卵数の操作 実験で使った巣とは別の 2 卵抱卵巣 4 ペア，3 卵抱卵巣と 4 卵抱卵巣それぞれ 3 ペアずっ, クラッチ内全ての卵の温度を測定した. 各卵には, 竹串で長径の先端に $3 \mathrm{~mm}$ ほどの穴をあ け, その穴からサーミスタプローブを卵内に $3 \mathrm{~cm}$ 程度挿入し, 入り口部分をテープで固定 した.これらの卵温測定用の卵を 24 時間程度抱卵させ, $\pm 0.1^{\circ} \mathrm{C}$ 精度で測定し 30 秒ごとに 記録した. プローブを挿入することによって卵内の胚は死ぬため, 胚自身による代謝活動の 卵温への影響はない。

親鳥に抱卵されているときの卵温を評価するため, 調査の妨害によって親鳥が抱卵してい ない可能性のある測定開始後 3 時間と終了前30分のデー夕は除外した. また, 抱卵交代な どで卵温が急激に減少, その後の上昇している間, 前後30分間は分析から除いた。 1 回 24 時間の測定毎に各卵の平均温度を計算し, クラッチ毎に卵温度の平均値を求めた。この值 について一元配置の分散分析を行い, Scheffeの方法で各抱卵数の間を多重比較した.

\section{4 ）抱卵中の親鳥の体温}

親鳥の体温の測定は, 体内埋め込み型温度測定用トランスミッター（Televilt 社, 大き さ: $1 \mathrm{~cm} \times 1 \mathrm{~cm} \times 2 \mathrm{~cm}$, 重さ : $3.6 \mathrm{~g}$ 形状 : 円柱状, 周波数 $(\mathrm{Hz}): 147.00-148.00)$ と 受信機 (Televilt社) を用いて行なった. 温度測定用トランスミッターは外科手術によって 親鳥の腹腔内に埋め込んだ．産卵終了後約 2 週間経過した 3 卵を抱卵している親鳥の内 3 ペアから各 1 個体ずつ捕獲し, 実験室内に持ち帰り, 麻酔（イソフルレン）をかけ, 抱卵 斑部の皮膚を正中線に沿って $3 \mathrm{~cm}$, 腹筋を $2 \mathrm{~cm}$ 切開した. あらかじめ糸を取り付けておい た温度測定用トランスミッターを, 腹腔側に位置するように腹筋に結び付け, 固定してから 腹筋と抱卵斑部の皮虞を縫合した。捕獲してから解放するまでに要した時間は 2 時間程度 
であった. 2 時間のうち麻酔から覚醒させるための時間として45分程度要した. トランスミッ ターを取り付けた個体が, 解放後再び抱卵していることを確認した. トランスミッターは生 体反応抑制シリコンで包埋してあるので, 生体反応による患部の発熱は最小限であったと 思われる. トランスミッターの温度の校正は，水銀計を用いて $30.0^{\circ} \mathrm{C}$ から $45.0^{\circ} \mathrm{C}$ の間で士 $0.1^{\circ} \mathrm{C}$ 精度で行った.

体温の測定は, 1 回につき 24 時間行った. トランスミッターを取り付けた各個体に 2 卵, 3 卵，4 卵を，それぞれ一昼夜ずつ抱卵させ，その間の体温を 30 秒ごとに記録した．受信 用のホイップアンテナ（長さ $20 \mathrm{~cm}$ ) を巣材の中に抱卵を妨げないように差し込み, 防水し た受信機を巣から $3 \mathrm{~m}$ 離れた位置に置いた。 受信可能な距離は $1 \mathrm{~m}$ 程度であったので, トラ ンスミッターからのデータを受信できている時は, 抱卵しているあのとみなした． 各測定期 間において, トランスミッターを取り付けた個体が抱卵を行わないことああったため, 最終 的にデータを得られたのは， 2 卵， 3 卵，4 卵とあに，延べ 2 個体ずっだった。 1 回の測 定毎に体温の平均値を求め, その平均値について一元配置の分散分析を行った.

\section{結 果}

\section{1 ) 抱卵数操作実験}

抱卵数を操作する前では，2 卵区，3 卵区，4 卵区の間で，産卵日と卵体積には有意な 差がなかった（Table 1)。しかし，卵重は操作実験区間で有意な差があった。4 卵区の卵

Table 1. Differences in egg laying dates, egg masses and egg volumes among 2-egg-manipulated, 3-egg-control and 4-egg-manipulated clutches. Egg laying date is counted from May-1 as day 1 . Means are given with \pm S.D. Sample sizes (number of eggs) are given in parentheses.

\begin{tabular}{lcccccc}
\hline & \multicolumn{3}{c}{ Experimental clutch sizes } & & \\
\cline { 2 - 4 } & 2-eggs(n=72) & 3-eggs $(\mathrm{n}=90)$ & 4-eggs $(\mathrm{n}=72)$ & & $\mathrm{F}_{2,225}$ & $p$ \\
\hline Laying date(day) & $16.8 \pm 3.85$ & $15.8 \pm 4.83$ & $16.4 \pm 3.38$ & 1.30 & n.s. \\
Egg mass(g) & $100.5 \pm 7.27$ & $101.0 \pm 7.47$ & $103.4 \pm 7.80$ & 3.20 & $<0.05$ \\
Egg volume(cm) & $90.4 \pm 6.76$ & $90.7 \pm 6.91$ & $92.8 \pm 7.21$ & 3.69 & n.s. \\
\hline
\end{tabular}

は 2 卵区よりあ有意に $2.9 \%$ 重かった（Scheffe's test: $p<0.05)$.

c卵 $(74.4 \%, \mathrm{n}=78)$ は, a卵 $(87.0 \%, \mathrm{n}=77)$, b卵 $(87.2 \%, \mathrm{n}=78)$ に比へ, 孵化 率が低い傾向にあった $\left(\chi^{2}\right.$ 検定 $\left.: \mathrm{df}=2, \chi^{2}=5.921, p=0.052\right)$. しかし, 卵数の操作後, 各実験区に含まれるa卵, b卵及びc卵の比率は変わらなかったので $\left(\chi^{2}\right.$ 検定 $: \mathrm{df}=4, \chi^{2}=$ 0.64, n.s.)，実験区間の比較をするときにa，b，c卵の影響は無視できる．孵化率は，実験 区間で有意な差はなかった (Table 2). 各グループの 1 巣当たり卯化した雛の数は, 2 卵 区で1.75 $\pm 0.44(n=24)$. 羽, 3 卵区で $2.53 \pm 0.73 （ n=30 ）$ 羽， 4 卵区で $3.17 \pm 0.94$ $(\mathrm{n}=24)$ 羽となり, 抱卵する卵の数が増加するにつれ粰化した雊の数す有意に増えた $\left(\mathrm{F}_{2,74}=\right.$ 22.57, $p<0.001$, 各実験区間とも Scheffe's test: $p<0.001)$.

抱卵日数には操作実験区の間で有意な差があり（Table 2), 各操作実験区毎に比べると 
Table 2. Hatching success, incubation periods, and hatchling masses of 2-eggmanipulated, 3-egg-control and 4-egg-manipulated clutches. Means are given with \pm S.D. Sample sizes (number of eggs) are given in parentheses.

\begin{tabular}{lccccc}
\hline \multicolumn{6}{c}{ Experimental clutch sizes } \\
\cline { 2 - 5 } & 2-eggs & 3-eggs & 4-eggs & \\
\hline Hatching success(\%) & $87.5(\mathrm{n}=48)$ & $84.4(\mathrm{n}=90)$ & $78.1(\mathrm{n}=96)$ & $\mathrm{X}^{2}=1.9, \mathrm{df}=2$ & n.s. \\
Incubation period(days) & $28.1 \pm 1.4(\mathrm{n}=42)$ & $28.2 \pm 1.6(\mathrm{n}=76)$ & $29.2 \pm 1.9(\mathrm{n}=75)$ & $\mathrm{F}_{2,190}=8.8$ & $p<0.05$ \\
Hatchling mass(g) & $72.4 \pm 7.2(\mathrm{n}=42)$ & $71.8 \pm 7.5(\mathrm{n}=76)$ & $72.6 \pm 8.4(\mathrm{n}=75)$ & $\mathrm{F}_{2,190}=0.2$ & n.s. \\
\hline
\end{tabular}

2 卵区と 3 卵区は餒化までにほぼ同じ日数を要しているが (Scheffe's test：n.s.)，4 卵区 はそれよりあ 1 日長くなっていた（2，3 卵区対 4 卵区, Scheffe's test: $p<0.01)$ ．邘化 した㮲の体重は, 各グループ間で差はなかった（Table 2).

\section{2 ) 卵温度の測定}

卵温度は各抱卵数の間で有意な差が見られ (one-way ANOVA: $\mathrm{F}_{2,7}=8.85, p<0.05$ ), 4 卵抱卵巣 $\left(33.0 \pm 2.8^{\circ} \mathrm{C}, \mathrm{n}=3\right)$ では 2 卵抱卵巣 $\left(36.2 \pm 1.8^{\circ} \mathrm{C}, \mathrm{n}=4\right.$, Scheffe's test: $p<0.05)$ や 3 卵抱卵巣 $\left(35.9 \pm 1.8^{\circ} \mathrm{C}, \mathrm{n}=3\right.$, Scheffe's test: $\left.p<0.05\right)$ に比べ, 卵温度 が低かった.

\section{3 ）抱卵体温の測定}

抱卵している親鳥の体温は, 2 卵抱卵時には $39.4^{\circ} \mathrm{C}(\mathrm{n}=2), 3$ 卵抱卵時には $39.5^{\circ} \mathrm{C}(\mathrm{n}=$ 2), 4 卵抱卵時には $40.3^{\circ} \mathrm{C}(\mathrm{n}=2)$ で，各抱卵数区間で差はなかった (one-way ANOVA : $\mathrm{F}_{2,3}=3.36$, n.s.).

\section{考察}

抱卵数の操作実験では各実験区問で卵重に有意な差が見られた（Table 1)，その原因は 不明であるが, 各実験区のすべてのペアは, 卵を 3 つ産卵しており，また，産卵日と卵体 積には有意な差がなかったことから，各実験区のペアに質的な差がないあのとみなす. 抱卵数操作実験において，4 卵区では，2 卵区や 3 卵区より捊化日数が 1 日長くなってい た (Table 2). 抱卵期間が延びると, 捊化時の親鳥のコンディションが低下したり (Tombre \& Erikstad 1996), 卵が捕食される危険性が高まる (Clark \& Wilson 1981) 等の影響があるが, 今回の実験では 1 日 $(3.5 \%)$ 延びただけなので, それらの影響がある

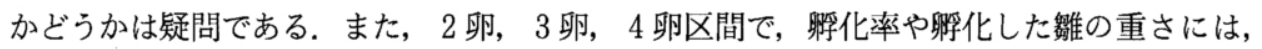
有意な差は見られず, 結果的に抱卵数が増えるとともに巣あたりの孵化した㮲数は増加し た. したがって，オオセグロカモメの 3 卵というクラッチサイズの上限は, 抱卵できる卵の 数には制限を受けていない. ワシカモメ (Larus glaucescens) の抱卵数の操作実験では, 4 卵や 5 卵を抱卵させたときに，巣当たりで捊化した雛の数は 3 卵を抱卵しているときと変 わらず, 増加した卵数に対応できていなかったが (Reid 1987a), 今回の実験では, オオセ 
グロカモメは，実験的に増加させた 4 卵には対応できていたようだ。ただし， c卵の捊化率 が，a卵，b卵にくらべて低い傾向にあることを考えると，自然条件で一腹卵数が 4 卵のと き, 後半に産まれた卵の卯孚化の可能性は低くなり, 期待されるよりあ巣立ち雛数は小さく なるかむしれない.

オオセグロカモメに 4 卵を抱卵させた時の卵温度は，2 卵や 3 卵を抱卵させた時よりあ低 かった，卵内の肧にとって温度は重要で，卵温が低いと，抱卵日数が長くなったり，孵化 率が低くなったり，捊化した雊のコンディションが悪くなったりする（Booth 1987， Williams 1996)。ッメバゲリ（Vanellus spinosus）の実験では， $37.5^{\circ} \mathrm{C}$ で温められた卵は,

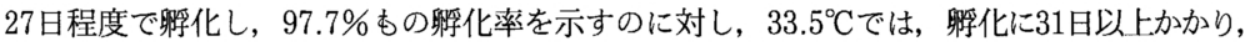
孵化率む70.6\%まで落ちた (Yogev et al. 1996). 抱卵数の操作実験で， 4 卵巣で餒化日 数が 1 日長くなっているのは，4 卵巣の卵は，低い温度で抱卵されていたためであろう．親 鳥は 4 卵を効率的に抱卵できていないと言える．ただし，孵化した雛の体重には実験区間 で差がなかったので, 抱卵時における卵数の増加がその後の薙の成長, 生存に大きく影響 しているかどうかは疑問である．親鳥の抱卵体温は，4 卵抱卵しているときは 2 卵 3 卵之 有意な差は認められず，抱卵数によって体温を調節しているとは言えない，したがって，4 卵を抱卵したときに，親鳥は増加したコストを補なっていないのか，物理的な制約によって うまく抱卵できていないようである (Szekely. et al. 1994).

結論として， 3 卵を 2 卵にした 2 卵区，3 卵を 4 卵にした 4 卵区，操作しない 3 卵区の 間で，粰化率や孵化した雛の体重に有意な差は見られなかったが，抱卵日数だけが 4 卵区 で 1 日長くなった．これは 4 卵を抱卵している時に卵温度が低くなったためである．ただし， この低温度む粰化率や雛の体重に影響を与える程のむのではなく，本研究では，4卵抱卵 することによる明白なコストは見つからなかった．アジサシの抱卵数の操作実験では，抱卵 数を増やしたときに, 梛化率や抱卵日数は変わらなかったが, 対照区に比べ雛の成長速度 が遅く, 親のコンディションが低下し, 増加した抱卵のコストの影響が示された（Heaney \& Monaghan 1996). したがって，オオセグロカモメでも育雛期になって，初めて抱卵コ ストの影響が現れる可能性は残される.

本論文をまとめる上で, 北海道大学農学部の齋藤裕教授, 長谷川英祐助手には, 計画段階からご指 導をいただき，原稿に目を通していただいた．国立極地研究所の加藤明子氏，黒木麻希氏，高橋晃周 氏及び依田憲氏には野外調查を手伝っていただいた：天売島の青塚松寿氏ならびに島民の方々には， 快適に調查をできるようお心遣いをいただいた．これらの方々のご好意に心からの謝意を表したい。

\section{摘要}

カモメ属の一腹卵数は通常 $2 \sim 3$ 卵である. 本研究では, 4 卵を抱卵するコストが, オオセグロカ モメの一腹卵数を制限する要因であるのかどうかを, 抱卵数の操作実験, 卵温度及び親鳥の抱卵体温 を測定することによって検証した．３卵を産卵した巣から 1 卵取り除いて 2 卵区，1 卵加えて 4 卵区 及び操作を行わないで 3 卵区を設けたところ，躬化率と粰化雅体重は，実験区間で有意な差が見られ なかったが，抱卵日数は，4 卵区が 2 卵区や 3 卵区よりも 1 日長くなっていた。サーミスターを入れ た温度測定用の卵を抱かせ，卵温度を測定したところ， 2 卵と 3 卵を抱卵しているときの卵温度は, それぞれ $36.2 \pm 1.8^{\circ} \mathrm{C} ， 35.9 \pm 1.8^{\circ} \mathrm{C}$ を示していたが， 4 卵を抱卵させた場合は， $33.0 \pm 2.8^{\circ} \mathrm{C}$ まで低下 
し 4 卵を効率よく抱卵できていなかった。 したがって，オオセグロカモメは 4 卵を効率よく抱卵できて いないが，それは粰化の成績や躬化雅の体重に強く影響するほどではない.

\section{引用 文 献}

Biebach, H., 1981. Energetic cost of incubation on different clutch sizes in Starling (Sturnus vulgaris). Ardea 69: 141-142.

Booth, D.T., 1987. Effect of temperature on development of Mallee Fowl Leipoa ocellata eggs. Physiol. Zool. 60: 437-445.

Clark, A.B., \& Wilson, D.C., 1981. Avian breeding adaptations : hatching asynchrony, brood reduction, and nest failure. Q. Rev. Biol. 56: 253-277.

Conover, M.R., 1984. Occurrence of supernormal clutches in the Laridae. Willson Bull. 96: 249-267.

Haftorn, S., \& Reinertsen, R. E., 1985. The effect of temperature and clutch size on the energetic cost of incubation in a free-living Blue Tit (Parus caeruleus). Auk 102: $470-478$.

Harris, M. P., \& Plumb, W. J., 1965 Experiments on the ability of Herring gulls (Larus argentatus) and Lesser black-backed gulls ( $L$. fuscus) to raise larger than normal brood. Ibis 107: 256-257.

Haymes, G. T., \& Morris, R. D., 1977 Brood size manipulations in Herring gulls. Can. J. Zool. 55: 1762-1766.

Heaney, V., \& Monaghan, P., 1996. Optimal allocation of effort between reproductive phases: the trade-off between incubation cost and subsequent rearing capacity. Proc. R. Soc. B. 263: 1719-1724.

Lack, D., 1947. The significance of clutch size. Ibis 89: 302-352.

Moreno, J., \& Carlson, A., 1989. Clutch size and the costs of incubation in the pied flycatcher Ficedula hypoleuca. Ornis Scand. 20: 123-128.

Monaghan, P., \& Nager, R. G., 1997. Why don't birds lay more eggs? Trends Ecol. Evol. 12: 270-274.

Monaghan, P., Nager, R. G., \& Houston, D. C., 1998. The price of eggs: increased investment in egg production reduces the offspring rearing capacity of parents. Proc. R. Soc. Lond. B. 265: 1731-1735.

Pierotti, R., \& Bellrose, C. A., 1986. Proximate and ultimate causation of egg size and the "third-chick" disadvantage in the Western Gull. Auk 103: 401-407.

Reid, W. V., 1987 a. Constraints on clutch size in the Glaucous-Winged Gull. Studies in Avian Biology 10: 8-25.

Reid , W. V., 1987 b. The cost of reproduction in the Glaucous-Winged Gull. Oecologia 74: 458-467.

Szekely, T., Karsai, I., \& Williams, T. D., 1994. Determination of clutch size Kentish Plover Charadrius alexandrinus. Ibis 136: 341-348.

Tombre, I. M., \& Erikstad, K. E., 1996. An experimental study of incubation effort in high Arctic barnacle geese. J. Anim. Ecol. 65: 325-331.

Williams, J. B., 1996. Energetics of avian incubation. Caray, C. (ed.) Avian Energetics and Nutritional Ecology: 375-416. Chapman and Hall, New York.

Winkler, D.W., 1985. Factors determining a clutch size reduction in California Gulls (Larus californicus): a multi-hypothesis approach. Evolution 39: 667-677.

Yogev, A., Ar, A., \& Yom-Tov, Y., 1996. Determination of clutch size and the breeding biology of Spur-winged Plover (Vanellus spinosus) in Israel. Auk 113: 68-73. 